Notes on Number Theory and Discrete Mathematics

Print ISSN 1310-5132, Online ISSN 2367-8275

Vol. 24, 2018, No. 4, 1-2

DOI: 10.7546/nntdm.2018.24.4.1-2

\title{
Happy $\varphi(164)$-th birthday, Prof. Tony Shannon!
}

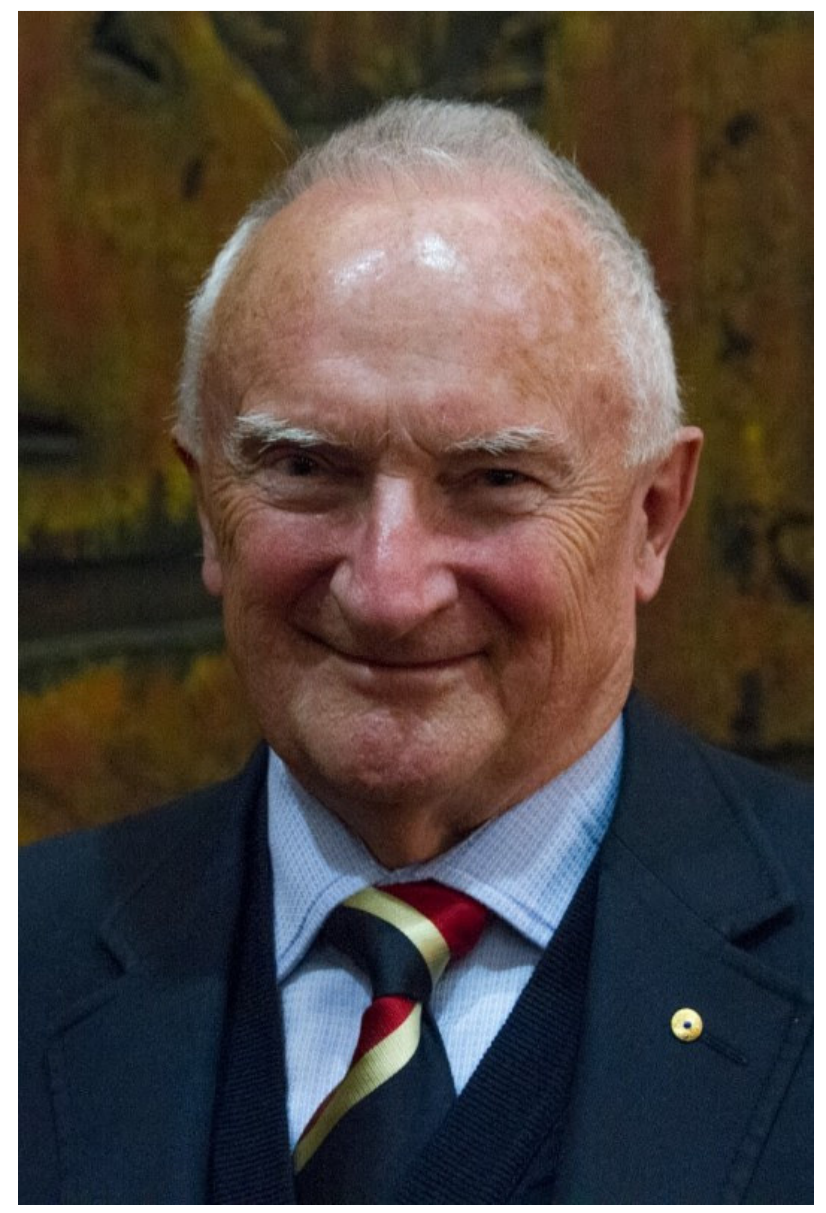

All readers of the "Notes on Number Theory and Discrete Mathematics" know Prof. Tony Shannon very well. For his 60-th and 75-th anniversaries, we dedicated papers in NNTDM Vol. 4 (1998), No. 2 and Vol. 19 (2013), No. 3, presenting some of his major results in number theory, but he continues actively to expand the list of his scientific results and achievements. Only for the last five years, he was or continues to be:

- Member of the Academic Board, Australian College of Physical Education, (2016-2018 Chair), between 2008-2018

- Senior Policy Advisor, Council of Private Higher Education, Inc., between 2011-2015

- Chair, Academic Board, Academy of Information Technology, Sydney, Melbourne, Brisbane, between 2012-2018 
- Adjunct Professor, Central Queensland University, between 2013-2016

- Registrar, Campion College Australia, between 2014-2016

- Deputy Chancellor, University of Notre Dame Australia, Sydney, Fremantle, Broome, between 2016-2017

- Director of Academic Affairs, Australian Institute of Music, Sydney and Melbourne, between 2016-2018

- Academic Dean, Elite Education Institute, Sydney \& Melbourne, since 2017

- Associate, PhillipsKPA Management Consultancy, since 2018

and what is the most important for us: for already 24 years he has been one of the three Editors-in-Chief of the "Notes on Number Theory and Discrete Mathematics" and one of its most active contributors.

Meantime, this year, Prof. Shannon and his longterm collaborator Jean V. Leyendekkers published the book "The Fibonacci Numbers and Integer Structure: Foundations for a Modern Quadrivium” (Nova Science Publishers, ISBN: 978-1-53613-454-4).

The book contains a collection of readily accessible classical problems, most of which can be linked to the sequence of Fibonacci integers and explained with integer structure analysis. Modular rings are used to solve, prove and extend a variety of number theory problems associated with generalized Fibonacci numbers, golden ratio families and primes, and distinctions between prime and composite integers, as well as the classical conjectures of Brocard-Ramanujan and ErdösStrauss. Another important structural feature is the rightend-digit (RED) of an integer - its value modulo 10. No matter the sizes of integers, operations with their REDs are stable; for instance, the sum of the integers

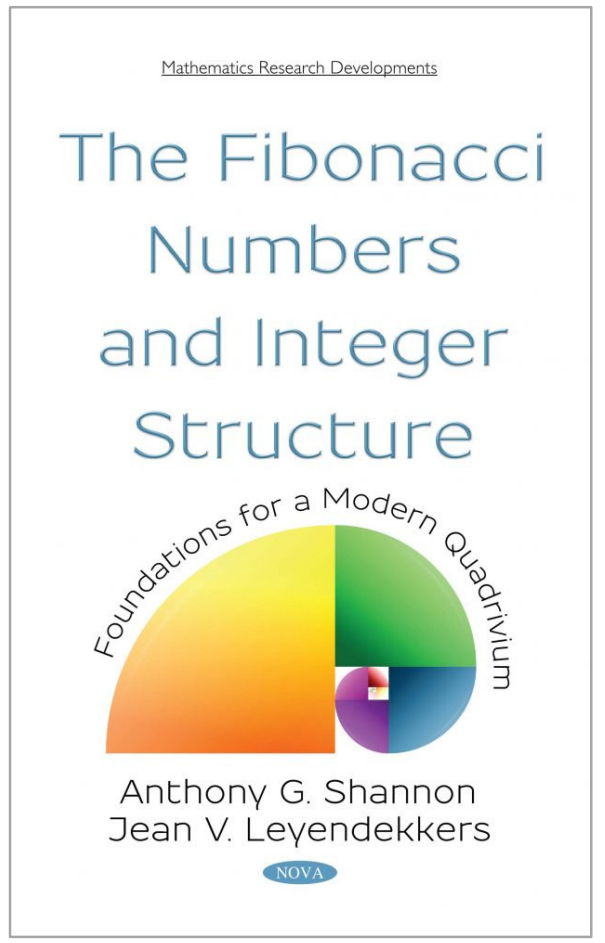
abcde 2 and ghabj5 has a RED of 7. This stability is exploited in several chapters so that powers are reduced to 4 types in the ring modulo 4 which, for example, clarifies Fermat's Last Theorem for some powers. The context of this very interesting book by Shannon and Leyendekkers is the teaching and learning of mathematics. This happens in historical and sociological contexts, and the text has sufficient historical and philosophical allusions for anyone to see that mathematics per se transcends race and religion, history and geography.

We hope that by his 164-th anniversary Prof. Shannon will delight us with his next scientific achievements and public service activities.

Happy birthday, Tony!

Krassimir T. Atanassov

József Sándor 